\title{
Microfiltration of Buttermilk and Washed Cream Buttermilk for Concentration of Milk Fat Globule Membrane Components
}

\author{
P. Morin, ${ }^{\star 1}$ M. Britten, ${ }^{\star}$ R. Jiménez-Flores, $†$ and Y. Pouliotł \\ ${ }^{*}$ Food Research and Development Centre, Agriculture and Agri-Food Canada, 3600 Casavant Blvd. West, St-Hyacinthe, PQ, Canada, J2S 8E3 \\ †Dairy Products and Technology Center, California Polytechnic State University, San Luis Obispo 93407 \\ ‡STELA Dairy Research Group, Institute of Nutraceuticals and Functional Foods (INAF), Université Laval, Quebec City, PQ, Canada, G1K 7P4
}

\section{ABSTRACT}

Buttermilk, the by-product from butter manufacture, has gained much attention lately because of the application potential of its milk fat globule membrane (MFGM) components as health ingredients. Microfiltration (MF) has been studied for buttermilk fractionation because of its ability to separate particles from dissolved solutes. However, the presence in this by-product of skim milk solids, especially casein micelles, restricts concentration of MFGM. The use of cream washed with skim milk ultrafiltrate to produce buttermilk with lower casein content was studied as well as fractionation of this buttermilk by MF. Results have shown that washing the cream prior to churning yields buttermilk with $74 \%$ less protein than normal cream buttermilk. Analysis of the protein profile of washed cream buttermilk revealed that caseins and whey proteins were the main classes of proteins removed. The MF of washed cream buttermilk resulted in permeation fluxes 2 -fold higher than with normal cream buttermilk. The second separation of the cream induced high losses of phospholipids in the skim phase. However, retention of remaining phospholipids in washed cream buttermilk by the MF membrane was higher resulting in a phospholipids concentration factor $66 \%$ higher than that of normal cream buttermilk. The results presented in this study highlight the impact of casein micelles on the separation of MFGM components as well as their effect on permeation flux during MF.

Key words: buttermilk, microfiltration, cream, milk fat globule membrane

\section{INTRODUCTION}

When cream is churned into butter, the aqueous phase of the cream is released from the butter mass and recovered as a by-product called buttermilk. The worldwide production of butter is growing and has

Received December 11, 2006.

Accepted January 4, 2007.

${ }^{1}$ Corresponding author: morinpi@agr.gc.ca reached $8.2 \times 10^{6}$ t in 2005 (FAOSTAT, 2006). Churning of $1 \mathrm{~kg}$ of $40 \%$ milkfat cream will generate roughly equal parts of butter and buttermilk, so worldwide production of buttermilk can be estimated to be close to that of butter production. Buttermilk does find many applications and is mainly processed into buttermilk powder, which has limited functional properties. Buttermilk can be added to prepared dried mixes, baking goods, or to various other dairy products (International Dairy Foods Association, 2003). Despite these various applications of buttermilk powder, its added value is still minimal and its full potential still remains to be exploited.

As opposed to skim milk, whole milk, and cream, buttermilk contains 4,5 , and 10 times more phospholipids on dry basis, respectively (Christie et al., 1987; Rombaut et al., 2005). When milk fat globules are broken by the high shear rate of the butter churn, parts of the membrane (milk fat globule membrane; MFGM) are recovered in the buttermilk. The MFGM is rich in various membrane proteins and phospholipids (Walstra et al., 2006). Some recent data suggest that MFGM might possess various biological properties of interest. In a recent review, Spitsberg (2005) described the potential nutraceutical properties of various components of the MFGM. For example, BRCA1 and BRCA2, both high molecular weight minor MFGM proteins, have been associated with cancer cell growth inhibition, whereas butyrophilin was tested for suppression of multiple sclerosis in mice model. Phospholipids from MFGM could also play an important role in cognitive functions (Ruenberg, 2002), and sphingomyelin has been linked with colon cancer cell inhibition (Schmelz et al., 2000).

In buttermilk, MFGM represent less than $5 \%$ of total solids. An appropriate process is then required to isolate or concentrate these components. Many attempts for buttermilk fractionation have been reported. Most of them used membrane filtration to selectively separate MFGM components from other buttermilk solids. Microfiltration (MF) has been used to fractionate buttermilk at different temperatures using various membrane pore sizes (Surel and Famelart, 1995; Astaire et 
al., 2003; Morin et al., 2004). Considering the highly variable sizes of the MFGM fragments in buttermilk ( 0.1 to several $\mu \mathrm{m}$; Morin et al., 2007), it is almost impossible to retain all MFGM fragments in the retentate using membranes with pore sizes greater than 0.1 $\mu \mathrm{m}$. However, the use of low pore sizes does not allow permeation of micellar casein. All the studies dealing with buttermilk MF led to the conclusion that the retention of casein micelles is very similar to that of MFGM components. The challenge for buttermilk fractionation using $\mathrm{MF}$ is to find conditions to retain a maximal amount of MFGM as well as remove other buttermilk solids. However, it appears almost impossible to separate casein micelles from MFGM by MF only. Other strategies are required to remove or dissociate casein micelles prior to filtration. Corredig et al. (2003) reported a process using sodium citrate to disrupt casein micelles prior to membrane filtration. Although casein transmission was improved, the MF permeate was contaminated with citrate at a concentration about 4-fold higher than found in normal milk (Surel and Famelart, 1995). Others have used rennet coagulation of buttermilk to eliminate casein prior to membrane filtration (Sachdeva and Buchheim, 1997), but rennet curds from buttermilk are weak and coagulation requires addition of high levels of calcium chloride. Furthermore, a significant proportion of MFGM is retained in casein curd and lost in the process. It has been shown in a previous work (Morin et al., 2006) that buttermilk obtained from churning of whey cream represents a valuable source of MFGM components that can be concentrated by MF. However, the low volumes of whey cream produced around the world, and the higher susceptibility to oxidation of whey butter can decrease the interest for this approach. In a recent work, Britten et al. (2007) have developed an approach based on cream washing to remove casein from the cream prior to churning. In the process, cream is separated from milk and then mixed to a ratio of $1: 10$ with milk ultrafiltrate, and then the cream is separated again yielding a cream with low amount of milk proteins. Buttermilk from washed cream has therefore much less caseins and should be an ideal substrate for MFGM concentration by MF.

The goal of the present study was to evaluate the effect of washing the cream on the separation of MFGM from buttermilk by MF. The investigation focused on the hydrodynamic filtration parameters and the composition of the fractions obtained.

\section{MATERIALS AND METHODS}

\section{Preparation of Buttermilks}

Washed Cream Buttermilk. Fresh raw milk (550 L) was obtained from a local dairy farm (Ferme SMA,
Beauport, Quebec, Canada). Raw milk was heated to $38^{\circ} \mathrm{C}$ in a UHT system (Chalinox, Sorel, Quebec, Canada) and was then separated into skim milk $(\sim 485 \mathrm{~kg})$ and cream $(\sim 65 \mathrm{~kg})$ using a milk separator (De Laval model No. 619, Lund, Sweden) running at $10,000 \times g$. Skim milk outlet of the separator was restricted to yield a cream of $\sim 30 \%$ fat. Skim milk was ultrafiltered on two $10-\mathrm{kDa}$ spiral-wound membranes mounted in parallel on a pilot scale system (Koch Filtration System, Koch Membrane Systems Inc., Wilmington, MA). Inlet and outlet pressures were set at 345 and $207 \mathrm{kPa}$, respectively. Filtration temperature was set to $50^{\circ} \mathrm{C}$, and the permeation flux during UF averaged $44.6 \pm 2.1 \mathrm{~L}$. $\mathrm{h}^{-1} \cdot \mathrm{m}^{-2}$. Skim milk was concentrated up to $3 \times$, and skim milk ultrafiltration permeate (SMUF) was collected. The SMUF was rapidly cooled to $4^{\circ} \mathrm{C}$ and stored overnight. Cream $(\sim 65 \mathrm{~kg})$ was diluted with 5 volumes of SMUF and gently mixed for $30 \mathrm{~min}$ before being separated again. The cream obtained from the separator had a fat content of $67 \pm 2 \%$. Cream was then standardized to $40 \%$ fat with the skim fraction. The cream was batch-pasteurized in a steam-jacketed tank at $66^{\circ} \mathrm{C}$ for $30 \mathrm{~min}$ and then cooled rapidly to $13^{\circ} \mathrm{C}$. Pasteurized washed cream was then churned in a rotary butter churn into butter and buttermilk. Churning was carried out at $26 \mathrm{rpm}$ and $13^{\circ} \mathrm{C}$. Buttermilk was collected and filtered through a stainless steel mesh. Butter was further churned to recover trapped buttermilk. Buttermilk was then quickly heated to $38^{\circ} \mathrm{C}$ and separated to remove excess lipids. This protocol was performed in triplicate.

Normal Cream Buttermilk. Fresh raw milk (1,600 L) was obtained from a local dairy farm (Ferme SMA). Raw milk was heated to $38^{\circ} \mathrm{C}$ in a UHT system (Chalinox) and was then separated into skim milk ( 1,500 $\mathrm{kg})$ and cream $(\sim 100 \mathrm{~kg})$ using a milk separator (AlfaLaval model No. 619, Lund, Sweden) running at 10,000 $\times g$. Fat content of the cream was standardized to $40 \%$ by blending with skim milk resulting in a volume of $\sim 160 \mathrm{~L}$ and was batch-pasteurized as described above. Cream was divided in 3 lots of $50 \mathrm{~kg}$ each. Each lot of cream was churned; buttermilk was recovered and separated as described above.

\section{MF Experiments}

MF Equipment. The MF module used for buttermilk filtration was a Tetra Alcross Pilot M1 (Tetra Pak Filtration Systems, Lund, Sweden) with permeate cocurrent recirculation allowing for low and uniform transmembrane pressure. The membrane used in this study was a 0.5- $\mu \mathrm{m}$ ceramic Membralox P35-37 membrane (Pall Corporation, Mississauga, Ontario, Canada) with $0.35-\mathrm{m}^{2}$ filtration surface. Clean distilled water (DI) 
water flux at $50^{\circ} \mathrm{C}$ and $100 \mathrm{kPa}$ transmembrane pressure was $2,866.3 \mathrm{~L} \cdot \mathrm{h}^{-1} \cdot \mathrm{m}^{-2}$, which corresponds to a hydraulic resistance of $0.035 \mathrm{kPa} / \mathrm{L} \cdot \mathrm{h}^{-1} \cdot \mathrm{m}^{-2}$. Before each run, the membrane was conditioned by alkaline-chlorine washing using Ultrasil $25(0.01 \%, \mathrm{pH} 13)$ and XY$12\left(200 \mathrm{ppm} \mathrm{Cl}^{-}\right)$cleaning solution (Ecolab, Mississauga, Ontario, Canada).

MF of Buttermilks. For each MF run, $20 \mathrm{~kg}$ of buttermilk was used. Buttermilk was concentrated to $5 \mathrm{~kg}$ by $\mathrm{MF}$ (MF 4×). Parameters for MF were $50^{\circ} \mathrm{C}, 50 \mathrm{kPa}$ of transmembrane pressure with a pressure drop of 140 $\mathrm{kPa}$ through the length of the membrane. Once the MF $4 \times$ was reached, the retentate was collected from the system and a sample was withdrawn $(100 \mathrm{~mL})$. The system was then rinsed with DI water until reaching a clear permeate, and permeate flux was measured to evaluate irreversible fouling resistance of the membrane. The retentate was then diluted with 6 diavolumes of DI water $(30 \mathrm{~kg})$ at $50^{\circ} \mathrm{C}$ and placed back in the MF system. The diluted MF $4 \times$ retentates were then concentrated back to $5 \mathrm{~kg}$ resulting in a batch diafiltration factor of 6 (DF 6 $\times$ ). Pressure and temperature parameters for diafiltration were the same as for MF. Permeation fluxes were measured during MF and DF using a graduated cylinder and a stopwatch. Hydraulic resistance of the membrane $\left(\mathbf{R}_{\mathbf{M}}\right)$, resistance caused by reversible fouling and concentration polarization layer $\left(\mathbf{R}_{\mathbf{R F}}+\mathbf{R}_{\mathbf{G}}\right)$ and resistance caused by irreversible fouling $\left(\mathbf{R}_{\mathbf{I F}}\right)$ were calculated with the resistance in series model in which $J=\left[\mathrm{P}_{T} /\left(\mathrm{R}_{\mathrm{M}}+\mathrm{R}_{\mathrm{G}}+\mathrm{R}_{\mathrm{RF}}+\right.\right.$ $R_{I F}$ )], where $J$ is the flux and $P_{T}$ is the transmembrane pressure (Cheryan, 1998). Fouling coefficients $\left(\mathbf{F}_{\mathbf{C}}\right)$ were also calculated as proposed by Ramachandra Rao et al. (1995) with $F_{C}=1-\left(J_{R} / J_{W}\right)$, where $J_{R}$ is the water flux of the fouled membrane after rinsing, and $J_{W}$ is the pure water flux of clean membrane. $\mathrm{A} \mathrm{F}_{\mathrm{C}}$ of 0 indicates a membrane with no detectable irreversible fouling, and a $F_{C}$ of 1 is indicative of a completely fouled membrane. Rejection percentage (R\%) of buttermilk components after $\mathrm{MF} 4 \times$ and $\mathrm{DF} 6 \times$ were calculated using the equation $\mathrm{R}=\left[1-\left(\mathrm{C}_{\mathrm{P}} / \mathrm{C}_{\mathrm{R}}\right)\right] \times 100$ where $\mathrm{C}_{\mathrm{P}}$ and $\mathrm{C}_{\mathrm{R}}$ are concentration of the component in the permeate and retentate, respectively.

\section{Analytical Procedures}

Raw milks, creams, buttermilks, and MF fractions were analyzed for total protein using a nitrogen analyzer (Leco FP-528, Leco Corp., St. Joseph, MI) and a protein conversion factor of 6.38. Total solids were obtained by oven drying for $15 \mathrm{~h}$ at $102^{\circ} \mathrm{C}$, and ash was measured by incineration in a muffle furnace at $550^{\circ} \mathrm{C}$ for $20 \mathrm{~h}$.
Lipids were extracted using the Mojonnier ether extraction procedure, and lipid extracts were diluted to 5 $\mathrm{mg} / \mathrm{mL}$ in $2: 1$ chloroform:methanol and stored at $-20^{\circ} \mathrm{C}$ until further analysis. The lipid profiles of the buttermilks were obtained by HPLC equipped with an evaporative light scattering detector (ELSD) as described previously (Morin et al., 2004). Standards used for calibration were phosphatidylethanolamine (PE), phosphatidylcholine (PC), phosphatidylserine (PS), phosphatidylinositol (PI), and sphingomyelin (SM; SigmaAldrich, Oakville, Ontario, Canada) isolated from bovine tissues (PE, PS, PI, SM) or egg yolk (PC).

Protein profiles were obtained by SDS-PAGE (Laemmli, 1970) on a $13.5 \%$ bis-acrylamide gel using the Mini Protean III system (BioRad, Mississauga, Ontario, Canada). Samples from the 3 replicates were pooled, and all samples were diluted to $3 \mathrm{mg} \cdot \mathrm{mL}^{-1}$ of protein with reducing buffer. Samples were then heated into boiling water for $10 \mathrm{~min}$. Cream samples were centrifuged at $10,000 \times g$ for $5 \mathrm{~min}$, and the loading volume was collected below the lipid layer to avoid loading an excess of lipid in the gel (Ye et al., 2002). Wells of the gels were loaded with $25 \mu \mathrm{L}$ of samples resulting in $75 \mu \mathrm{g}$ of proteins loaded per well. Gels were run at $90 \mathrm{~V}$ until migration front reached the separating gel and $110 \mathrm{~V}$ for the remaining of the electrophoresis. Gels were stained with Coomassie blue and destained with a mixture of acetic acid, methanol, and DI water. Relative protein class (MFGM, caseins, and whey proteins) distribution in the samples was obtained by densitometry using Quantity One software from BioRad. Protein classes were determined according to their molecular weight by comparison with a molecular weight standard (Precision Plus unstained protein standard, BioRad).

\section{Statistical Analysis}

Results were analyzed statistically using Minitab 14.0 software package (Minitab Inc., State College, PA). The ANOVA procedures were performed, and mean comparisons were carried out using Tukey's test. Results were considered significantly different at $P<0.05$ and highly significant at $P<0.01$.

\section{RESULTS AND DISCUSSION}

\section{Effect of Cream Washing on Cream and Buttermilk Composition}

Shorter churning times $(P<0.05)$ were observed for washed creams compared with normal creams. Time required for emulsion breakdown (expressed in min per $\mathrm{kg}$ of cream) of washed and normal creams was $1.01 \pm$ 0.09 vs. $2.80 \pm 0.80$, respectively. When cream is churned into butter, a series of phenomena occurs. As 
Table 1. Average composition of pasteurized creams and buttermilks $( \pm \mathrm{SD}), \mathrm{n}=3$

\begin{tabular}{|c|c|c|c|c|}
\hline \multirow[b]{2}{*}{ Item } & \multicolumn{2}{|c|}{ Pasteurized cream } & \multicolumn{2}{|c|}{ Buttermilk } \\
\hline & Normal $^{1}$ & Washed & Normal & Washed \\
\hline Total solids (\%) & 44.21 & $39.92 \pm 3.53$ & $9.12 \pm 0.17^{\mathrm{a}}$ & $6.38 \pm 0.06^{\mathrm{b}}$ \\
\hline Total proteins (\%) & 2.11 & $0.87 \pm 0.07$ & $3.46 \pm 0.05^{\mathrm{a}}$ & $0.91 \pm 0.14^{b}$ \\
\hline Total lipids (\%) & 38.63 & $36.97 \pm 3.04$ & $0.51 \pm 0.02^{\mathrm{a}}$ & $0.33 \pm 0.01^{b}$ \\
\hline Phospholipids (\%) & $\mathrm{ND}^{2}$ & ND & $0.13 \pm 0.00^{\mathrm{a}}$ & $0.05 \pm 0.01^{\mathrm{b}}$ \\
\hline \multicolumn{5}{|c|}{ Class distribution $^{3}(\%)$} \\
\hline $\mathrm{PE}$ & - & - & $33.88 \pm 0.55^{\mathrm{a}}$ & $21.70 \pm 1.61^{b}$ \\
\hline $\mathrm{PC}$ & - & - & $33.23 \pm 1.92^{\mathrm{a}}$ & $45.70 \pm 0.69^{b}$ \\
\hline PS & - & - & $6.18 \pm 0.45^{\mathrm{a}}$ & $5.16 \pm 0.18^{\mathrm{b}}$ \\
\hline PI & - & - & $11.06 \pm 1.00$ & $10.95 \pm 0.56$ \\
\hline SM & - & - & $15.66 \pm 0.80$ & $16.49 \pm 1.20$ \\
\hline $\operatorname{Ash}(\%)$ & 0.39 & $0.31 \pm 0.04$ & $0.77 \pm 0.06^{\mathrm{a}}$ & $0.47 \pm 0.03^{b}$ \\
\hline
\end{tabular}

\footnotetext{
${ }^{\mathrm{a}, \mathrm{b}}$ Significant difference $(P<0.05)$ between washed and normal cream buttermilk.

${ }^{1}$ One sample of pasteurized cream was taken as the cream was divided in 3 lots only after pasteurization.

${ }^{2} \mathrm{ND}=$ not determined.

${ }^{3} \mathrm{PE}=$ phosphatidylethanolamine, $\mathrm{PC}=$ phosphatidylcholine, $\mathrm{PS}=$ phosphatidylserine, $\mathrm{PI}$ = phosphatidylinositol, SM = sphingomyelin.
}

air is incorporated in the cream, skim milk proteins adsorb and unfold at the surface of the air bubbles, and then MFGM displaces the skim milk proteins, which induces rupture of the milk fat globules (Frede and Buchheim, 1994). Because of the washing procedure applied to the cream, the amount of skim milk proteins available to stabilize the foam interface was lower, which resulted in faster MFGM rupture and reduced churning time. The churning times were longer than those previously reported with the same equipment (Morin et al., 2007). The main reason for this difference is that no cold maturation was applied to the cream in the present investigation. Cold maturation ensures proper crystallization of triglycerides inside the milk fat globules to obtain the desired butter texture and limits fat losses to buttermilk (Mahaut et al., 2000). Cold maturation was not applied in our experiments because butter texture was not the main focus and that buttermilk was skimmed before MF. When recovered from the churn, washed cream butter texture was very similar to that of normal cream butter. However, washed and normal cream butter properties were not investigated in this experiment. The only difference that may be expected in the butter from washed cream could be a slightly lower protein level. This lower protein level could potentially induce lower browning properties for the washed cream butter. Also, considering that only one centrifugation step is added to the washed cream process, very little organoleptic differences are expected between the 2 butters.

Composition of pasteurized creams and buttermilks are listed at Table 1 . The most important effect observed was the decrease in the protein content. Britten et al. (2007) demonstrated a decrease of $80 \%$ in the protein content of buttermilk made from cream washed with 10 volumes of milk ultrafiltrate. Our results are in line with those of Britten et al. (2007) because the observed decrease in our experiments was $74 \%$ with cream washed with only 5 volumes of milk ultrafiltrate. The washing solution (skim) from the second separation of the cream therefore contains about $74 \%$ of the cream proteins. This feed can be concentrated by UF to yield a milk protein concentrate (MPC) and a permeate that can be reused to wash the cream, therefore yielding a process with very low output of by-products.

The protein profile of both creams and buttermilks were markedly different. As shown in the SDS-PAGE gels (Figure 1a and 1b, lanes 1 and 2), the proportion of caseins found in washed cream and buttermilk was lower than that of normal cream and buttermilk. Whey proteins, mainly $\beta$-LG, were also reduced by cream washing, but MFGM proteins proportion was higher in buttermilk from washed cream. The ratio of MFGM proteins to skimmed milk proteins in washed cream buttermilk, as estimated by densitometry, was 2.31 as opposed to 0.85 for normal cream buttermilk. The washing procedure therefore not only allowed important removal of proteins (74\%), but the proteins removed were mainly skim milk proteins, yielding buttermilk with increasing relative proportion of MFGM proteins.

Phospholipid quantification in the cream samples, using an HLPC-ELSD method, was difficult because of the very high ratio of neutral lipids to phospholipids in samples. However, Britten et al. (2007) have shown that a second separation of cream diluted 10 times with skim milk ultrafiltrate induced less than $20 \%$ loss in phospholipids. Compared with normal buttermilk, the phospholipids concentration in buttermilk obtained from washed cream was reduced by $60 \%$ (Table 1 ). Using a similar approach, Britten et al. (2007) observed 


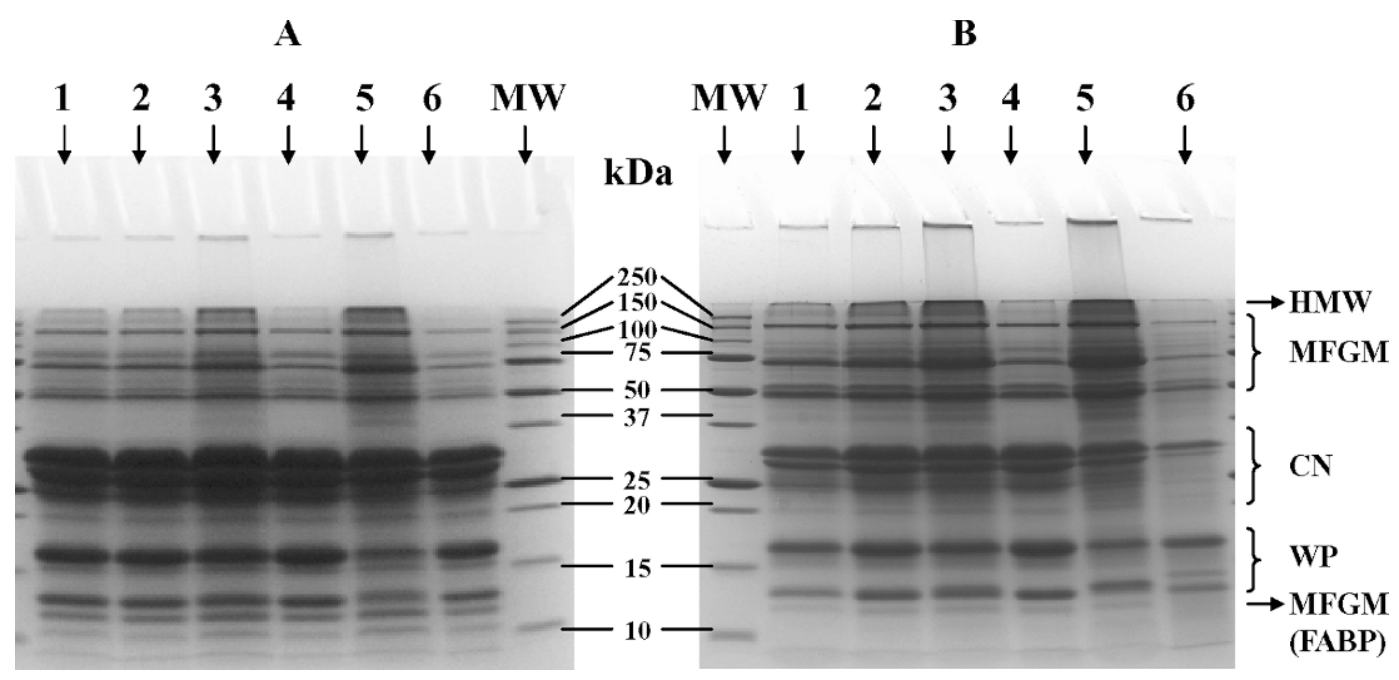

Figure 1. The SDS-PAGE (13.5\%) of normal cream samples (A) and washed cream samples (B). Lanes 1 are pasteurized creams, lanes 2 are buttermilks, lanes 3 are $4 \times$ microfiltration (MF) retentates, lanes 4 are $4 \times$ MF permeates, lanes 5 are $6 \times$ diafiltration (DF) retentates, and lanes 6 are $6 \times$ DF permeates. MW = molecular weight standards; HMW = high molecular weight material; MFGM = milk fat globule proteins; $\mathrm{CN}$ = caseins; $\mathrm{WP}$ = whey proteins; FABP = fatty acid binding protein (MFGM).

only a $30 \%$ decrease. Considering that cream-washing treatment does not affect phospholipid retention in butter (Britten et al., 2007), it appears that the washing conditions used in the present study induced severe phospholipids losses. A lower cream dilution factor was applied prior to the second separation. Using a conventional separator with higher fat content input (6\%) led to a $>60 \%$ fat washed cream, which induced excessive crowding and mechanical stress on fat globules. In such condition, partial churning during separation probably occurred, promoting the liberation of membrane material in the skim phase. This could have also contributed to the shorter churning times observed with washed cream. The distribution of phospholipids was significantly different in washed and normal cream buttermilks for PE, PC, and PS. This result suggests that the composition of phospholipids in MFGM is heterogeneous and that the release of membrane material during washing treatment could be selective. The asymmetric positioning of phospholipids in the MFGM has been suggested to explain profile modification in the course of dairy processes (Rombaut et al., 2006b; Morin et al., 2007). However, it is not clear why MFGM fragments with higher concentration of $\mathrm{PE}$ and lower concentration of PC were preferentially released by the washing procedure. Previous work has shown that PE content decreased after spray-drying of buttermilk (Morin et al., 2007). The observed decrease appears to be caused by processing that could induce modification in the structure of the MFGM resulting lower extraction levels using the Mojonnier extraction procedure. However, because washing of the cream in our study in- cluded no particular heat or concentrative treatment, a proportion PE may have been displaced from MFGM and recovered in the skim milk, therefore affecting the distribution of other phospholipids.

Ash content of buttermilk from washed cream was also lower than that of normal cream buttermilk. Casein micelles removal induced a decrease of colloidal calcium phosphate content in cream after washing.

\section{Microfiltration Flux and Membrane Fouling}

The average permeation flux values obtained during $4 \times \mathrm{MF}$-concentration and DF $6 \times$ of both buttermilks are shown at Figure 2. Flux obtained with washed cream buttermilk was about 2 -fold higher than for normal cream buttermilk. Lower solid content in washed cream buttermilk lowers viscosity and may explain higher flux values. However, because the total solids in washed cream buttermilk are only reduced by one-third (Table 1), the composition of these solids may have also influenced the flux improvement. Higher concentration of casein micelles in normal cream buttermilk can also explain the lower permeation flux. In fact, the casein micelles present in buttermilk are partly retained by a 0.5- $\mu \mathrm{m}$ MF membrane, and they can therefore accumulate in the concentration polarization layer $(\mathbf{C P})$ as a result of the convective flow toward the membrane.

The various contributions to the hydraulic resistance during filtration of both buttermilks are reported on Table 2. Reversible fouling and CP layer resistance $\left(R_{R F}\right.$ $\left.+\mathrm{R}_{\mathrm{G}}\right)$ were higher for normal cream buttermilk $(P<$ $0.01)$, whereas irreversible fouling resistance $\left(R_{I F}\right)$ was 


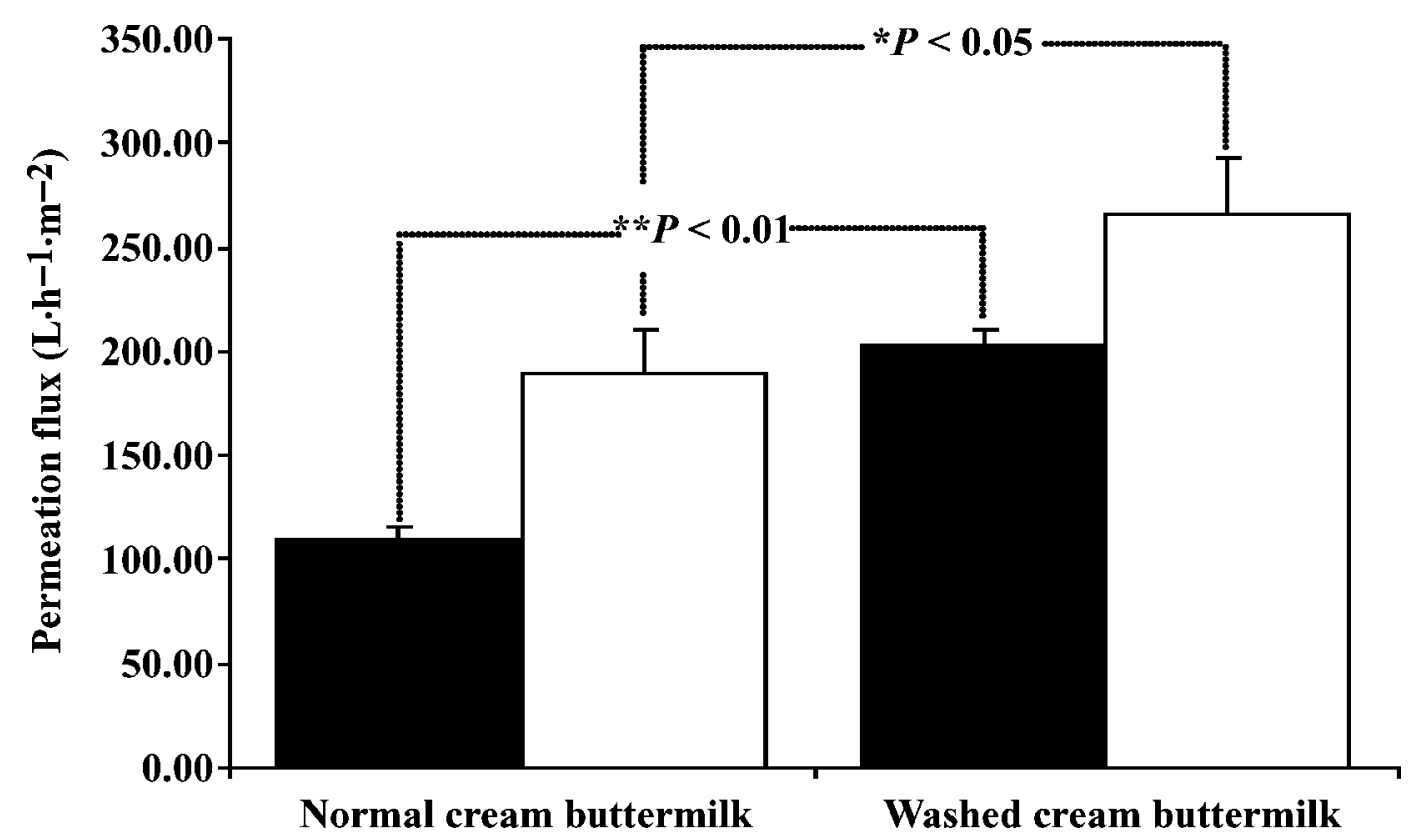

Figure 2. Average permeate flux during microfiltration (MF; $\mathbf{n})$ and diafiltration (DF; $\square$ ) of normal cream and washed cream buttermilk. Bars indicate SD.

higher for washed cream buttermilk $(P<0.05)$. Because casein micelles are the main protein component in normal cream buttermilk (Figure 1A), casein accumulates at the surface of the membrane, creating a porous layer that limits permeation but could also limit the deposition of fouling material at the surface of the membrane. Therefore it appears that for normal cream buttermilk, flux is mainly controlled by the CP layer and reversible fouling of the membrane. The reversible fouling resistance was more than 10 times higher than the irreversible fouling resistance for normal cream buttermilk MF, indicating that this material did not excessively foul the ceramic membrane.

In the case of washed cream buttermilk, the resistance caused by reversible fouling was approximately

Table 2. Membrane resistances calculated after microfiltration $4 \times$ of normal and washed cream buttermilks $( \pm \mathrm{SD}), \mathrm{n}=3$

\begin{tabular}{lcc}
\hline $\begin{array}{l}\text { Resistance } \\
\left(\mathrm{kPa} / \mathrm{L}^{-1} \mathrm{~h}^{-1} \cdot \mathrm{m}^{-2} \times 10^{2}\right)\end{array}$ & $\begin{array}{c}\text { Normal } \\
\text { cream } \\
\text { buttermilk }\end{array}$ & $\begin{array}{c}\text { Washed } \\
\text { cream } \\
\text { buttermilk }\end{array}$ \\
\hline$R_{M}{ }^{1}$ & 3.49 & 3.49 \\
$R_{R F}+R_{G}{ }^{2}$ & $39.50 \pm 2.26^{\mathrm{a}}$ & $13.74 \pm 2.62^{\mathrm{b}}$ \\
$R_{I F}{ }^{\mathrm{a}}$ & $2.91 \pm 0.28^{\mathrm{a}}$ & $7.38 \pm 2.26^{\mathrm{b}}$ \\
\hline${ }^{\mathrm{a}, \mathrm{b}}$ Significant difference $(P<0.05)$ between normal and washed \\
creams. \\
${ }^{1} R_{M}=$ hydraulic resistance of the membrane. \\
${ }^{2} R_{R F}+R_{G}=$ combined resistances caused by reversible fouling and \\
concentration polarization. \\
${ }^{3} R_{I F}$ and resistance caused by irreversible fouling.
\end{tabular}

3 times lower than that of normal cream buttermilk, indicating that the CP layer and the reversible fouling do restrict the permeation but to a much lower extent. A different CP layer, with a possibly thinner or more porous structure, is apparently formed during MF of washed cream buttermilk. However, the irreversible fouling resistance calculated after MF of washed cream buttermilk was about 2.5-fold higher than that of normal cream buttermilk. The fouling material remaining in washed cream buttermilk could be residual casein and whey proteins, small fat globules, ionic calcium, and MFGM material. The lower casein micelle concentration prevents the formation of a porous layer at the membrane surface and allows fouling material to interact with the surface and within the pores of the membrane, which increases irreversible fouling. Overall, the permeation flux of the entire MF procedure can be doubled with washed cream buttermilk, but long-term MF of washed cream buttermilk may lead to severe fouling of the membrane. To represent the extent of the fouling of the membrane, $\mathrm{F}_{\mathrm{C}}$ was calculated and was 0.67 \pm 0.07 and $0.45 \pm 0.02$ for washed cream and normal cream buttermilk, respectively. Ultrafiltration of normal cream buttermilk on a polysulfonic membrane yielded an $\mathrm{F}_{\mathrm{C}}$ value of 0.67 (Ramachandra Rao et al., 1995), and an $F_{C}$ over 0.90 has been reported by Rombaut et al. (2006a) during MF of butterserum on a cellulose acetate $\mathrm{MF}$ membrane. Our $\mathrm{F}_{\mathrm{C}}$ values for normal cream buttermilk are lower than values reported reflecting the efficiency of the uniform transmembrane 
pressure filtration mode used in this experiment. Washed cream buttermilk $\mathrm{F}_{\mathrm{C}}$ was very similar to the value reported by Ramachandra Rao et al. (1995) for UF of normal cream buttermilk. Because permeation flux patterns reported by these authors were very stable for $60 \mathrm{~min}$, similar flux stability is expected for longer MF runs of washed cream buttermilk.

\section{Composition of MF Fractions}

The average compositions of MF and DF fractions from washed cream and normal cream buttermilks are shown at Table 3. Rejection rates were also calculated and are shown in Table 4 . Because washed cream buttermilk contained lower total solids than normal cream buttermilk $(P<0.01)$, composition data presented for $\mathrm{MF}$ and DF fractions in Table 3 are expressed on a dry basis. Washing the cream before churning reduced total protein content in $\mathrm{MF} 4 \times / \mathrm{DF} 6 \times$ retentate. The protein profile was obtained by SDS-PAGE and results are shown in Figure 1. The final washed cream buttermilk MF $4 \times / \mathrm{DF} 6 \times$ retentate contains much less casein than normal cream buttermilk MF $4 \times / \mathrm{DF} 6 \times$ retentate. Densitometry analysis of the gel revealed a ratio of MFGM proteins to caseins of 1.5 for MF $4 \times / \mathrm{DF} 6 \times$ retentate from normal cream buttermilk, whereas the same ratio was 4.4 in MF $4 \times / \mathrm{DF} 6 \times$ retentate from washed cream. However, densitometry data has to be interpreted with caution because it has been observed previously that intensity of staining with Coomassie blue is highly dependent of protein type and saturation of bands can lead to underestimation of concentration (Rombaut et al., 2006a). Whey proteins and caseins appeared to be mainly transmitted through the membrane, whereas MFGM proteins were mostly retained by the membrane. Although some MFGM proteins were observed in the permeate samples, it has to be considered that SDS-PAGE wells were loaded with an equal amount of protein, so even if small amounts of MFGM proteins are found in the permeate, they would represent a relatively small percentage in the permeates because their concentration in proteins are lower than the retentates. A lower pore size membrane $(<0.5 \mu \mathrm{m})$ could be used to limit losses of MFGM material in the permeate, but this would be detrimental to the permeation flux as well as the transmission of caseins.

Lipids were well retained by the membrane as the rejection coefficients were between 76 and 100\% (Table 4). The MF of washed and normal cream buttermilk using a $0.5-\mu \mathrm{m}$ membrane allowed some permeation of phospholipids through the membrane. This result was expected considering that MFGM proteins (bound to phospholipid in the MFGM) were also detected in the permeate samples. Observation of MFGM particles by

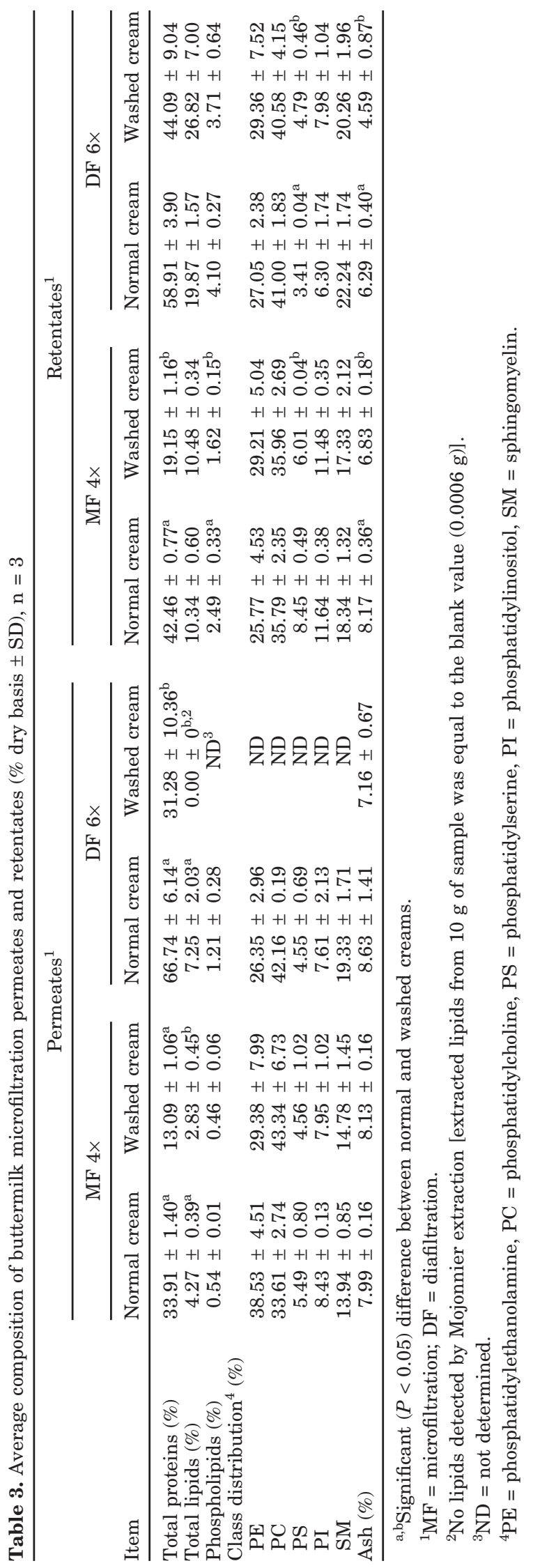


Table 4. Rejection percentage after microfiltration (MF) $4 \times$ and diafiltration (DF) $6 \times$ of washed and normal cream buttermilks $( \pm \mathrm{SD}), \mathrm{n}=3$

\begin{tabular}{|c|c|c|c|c|}
\hline \multirow[b]{2}{*}{ Item } & \multicolumn{2}{|c|}{ MF $4 \times$} & \multicolumn{2}{|c|}{ DF $6 \times$} \\
\hline & Normal cream & Washed cream & Normal cream & Washed cream \\
\hline Proteins & $54.04 \pm 2.53$ & $55.54 \pm 4.08$ & $66.08 \pm 5.16$ & $69.93 \pm 10.95$ \\
\hline Lipids & $76.25 \pm 2.17$ & $82.42 \pm 3.43$ & $88.98 \pm 3.44^{\mathrm{a}}$ & $100 \pm 0.00^{\mathrm{b}}$ \\
\hline Phospholipids & $88.75 \pm 0.68^{\mathrm{a}}$ & $81.52 \pm 3.58^{b}$ & $89.68 \pm 1.43^{\mathrm{a}}$ & $100 \pm 0.00^{b, 1}$ \\
\hline Ash & $43.62 \pm 3.66^{\mathrm{a}}$ & $22.69 \pm 1.23^{\mathrm{b}}$ & $58.89 \pm 8.39$ & $34.32 \pm 13.02$ \\
\hline
\end{tabular}

${ }^{\mathrm{a}, \mathrm{b}}$ Significant $(P<0.05)$ difference between normal and washed creams.

${ }^{1}$ No lipids detected in the permeate by Mojonnier extraction [extracted lipids from $10 \mathrm{~g}$ of sample was equal to the blank value $(0.0006 \mathrm{~g})]$.

electronic microscopy in previous work demonstrated the high variability in sizes ranging from 0.1 to 3 to 4 $\mu \mathrm{m}$ (Morin et al., 2007). Thus, it can be expected that smaller MFGM particles will permeate the membrane, and this was observed by several other workers (Surel and Famelart, 1995; Astaire et al., 2003; Morin et al., 2004, 2006; Rombaut et al., 2006a). The phospholipid class distribution appeared to be only slightly affected by the MF procedure (Table 3), which supports the view that mainly whole MFGM fragments were permeating the membrane rather than dissociated phospholipids. The important losses of phospholipids observed during cream washing treatment affected the composition of the final retentate fraction (MF $4 \times / \mathrm{DF} 6 \times$ ) as the percentage of phospholipids was slightly lower for washed cream buttermilk as compared with normal cream buttermilk (3.71 vs. $4.10 \%$ ). Nonetheless, $\mathrm{MF} 4 \times / \mathrm{DF} 6 \times$ of washed and normal cream buttermilk induced, respectively, a 4.6- and 2.8-fold increase in phospholipid content (dry basis). Higher phospholipids concentration factor in washed cream buttermilk is explained by the lower protein content, which results in more efficient elimination of solids during filtration. Phospholipids rejection by the MF membrane was significantly higher for normal cream buttermilk during MF $4 \times$ (Table 4). The establishment of the CP layer composed of casein micelles could have improved rejection by the membrane. Possible interactions between phospholipids and casein could also play a role in this higher rejection. When concentration increase was calculated on wet basis after MF $4 \times$, it was found that the increase was similar with both materials (2.1- and 2.2-fold, respectively). The real effect of concentration of phospholipids lies therefore more in the further removal of other solids in washed cream buttermilk after diafiltration than better rejection by the MF membrane.

\section{CONCLUSIONS}

Although washing the cream can induce more losses of MFGM material and reduces the yield of the whole process, it significantly improves the concentration of MFGM material from buttermilk by MF. Permeation flux in MF can also be drastically improved using this approach. This study clearly demonstrates the detrimental effect of caseins for both concentration of MFGM and the hydrodynamic parameters during membrane filtration of buttermilk. Given that losses of phospholipids during washing of the cream could be minimized, this approach can be useful to produce MFGM ingredients with increased purity without the use of solvent extraction or chemical addition to buttermilk. The process of washing the cream can be fully integrated in dairy processes as milk ultrafiltrate can be obtained from MPC manufacture, and the proteins recovered from washing the cream could also be concentrated to produce MPC. Sensory and functional characteristics of butter produced from washed cream remain to be investigated.

\section{ACKNOWLEDGMENTS}

This work was accomplished under a grant from Dairy Farmers of Canada. The authors would like to acknowledge the technical help of Pascal Cliche (LTA, Université Laval) and express gratitude to Anne-Cécile Gaonac'h (Université Laval) and Sophie Lamothe (Food Research and Development Centre, Agriculture and Agri-food Canada) for their collaboration in analytical work.

\section{REFERENCES}

Astaire, J. C., R. Ward, J. B. German, and R. Jiménez-Flores. 2003. Concentration of polar MFGM lipids from buttermilk by microfiltration and supercritical fluid extraction. J. Dairy Sci. 86:2297-2307.

Britten, M., S. Lamothe, and G. Robitaille. 2007. Effect of cream treatment on phospholipids and protein recovery in butter making process. Int. J. Food Sci. Technol. Accepted.

Cheryan, M. 1998. Ultrafiltration and Microfiltration Handbook. Technomic Publishing Co. Inc., Urbana, IL.

Christie, W. W., R. C. Noble, and G. Davies. 1987. Phospholipids in dairy products. J. Soc. Dairy Technol. 40:10-12.

Corredig, M., R. R. Roesch, and D. G. Dalgleish. 2003. Production of a novel ingredient from buttermilk. J. Dairy Sci. 86:2744-2750. 
FAOSTAT. 2006. Subject: 2005 World Butter and Ghee Production. http://faostat.fao.org Accessed May 26, 2006.

Frede, E., and W. Buchheim. 1994. Buttermaking and the churning of blended fat emulsions. J. Soc. Dairy Technol. 47:19-27.

International Dairy Foods Association. 2003. Dairy Facts 2003 Edition. Int. Dairy Foods Assoc., Washington, DC.

Laemmli, U. K. 1970. Cleavage of structural proteins during the assembly of the head of bacteriophage T4. Nature 227:680-685.

Mahaut, M., R. Jeantet, G. Brulé, and P. Schuck. 2000. Les produits laitiers industriels. Editions Tec \& Doc, Paris, France.

Morin, P., R. Jiménez-Flores, and Y. Pouliot. 2004. Effect of temperature and pore size on the fractionation of fresh and reconstituted buttermilk by microfiltration. J. Dairy Sci. 87:267-273.

Morin, P., R. Jiménez-Flores, and Y. Pouliot. 2007. Effect of processing on the composition and structure of buttermilk and its milk fat globule membranes. Int. Dairy J. Accepted.

Morin, P., Y. Pouliot, and R. Jiménez-Flores. 2006. A comparative study of the fractionation of regular buttermilk and whey buttermilk by microfiltration. J. Food Eng. 77:521-528.

Ramachandra Rao, H. G., M. J. Lewis, and A. S. Grandison. 1995. Effect of $\mathrm{pH}$ on flux during ultrafiltration of sweet whey and buttermilk. J. Dairy Res. 62:441-449.

Rombaut, R., V. Dejonckheere, and K. Dewettinck. 2006a. Microfiltration of butter serum upon casein micelle destabilization. J. Dairy Sci. 89:1915-1925.
Rombaut, R., J. Van Camp, and K. Dewettinck. 2005. Analysis of phospho- and sphingolipids in dairy products by a new HPLC method. J. Dairy Sci. 88:482-488.

Rombaut, R., J. Van Camp, and K. Dewettinck. 2006b. Phospho- and sphingolipid distribution during processing of milk, butter and whey. Int. J. Food Sci. Technol. 41:435-443.

Ruenberg, D, inventor. 2002. Anti-depressant, stress suppressor and mood improver. United States patent no. US 2002072508.

Sachdeva, S., and W. Buchheim. 1997. Recovery of phospholipids from buttermilk using membrane processing. Kieler Milch. Forsch. 49:47-68.

Schmelz, E. M., M. C. Sullards, D. L. Dillehay, and A. H. Merrill, Jr. 2000. Colonic cell proliferation and aberrant crypt foci formation are inhibited by dairy glycosphingolipids in 1, 2-dimethylhydrazine-treated CF1 mice. J. Nutr. 130:522-527.

Spitsberg, V. L. 2005. Invited review: Bovine milk fat globule membrane as a potential nutraceutical. J. Dairy Sci. 88:2289-2294.

Surel, O., and M. H. Famelart. 1995. Ability of ceramic membranes to reject lipids of dairy products. Aust. J. Dairy Technol. 50:36-40.

Walstra, P., J. T. M. Wouters, and T. J. Geurts. 2006. Dairy Science and Technology Handbook, Second Edition. Taylor and Francis Group, Boca Raton, FL.

Ye, A., H. Singh, M. W. Taylor, and S. Anema. 2002. Characterization of protein components of natural and heat-treated milk fat globule membranes. Int. Dairy J. 12:393-402. 